\title{
FLUXOS MIGRATÓRIOS EM PORTUGAL: DO BOOM MIGRATÓRIO À DESACELERAÇÃO NO CONTEXTO DE CRISE. BALANÇOS E DESAFIOS
}

\author{
Beatriz Padilla* \\ Alejandra Ortiz**
}

\begin{abstract}
A migração tem sido um fenómeno cada vez mais presente na sociedade portuguesa, tanto no que se refere à imigração como à emigração. $\mathrm{O}$ artigo apresenta um panorama resumido desta história recente, descrevendo não só os fluxos e as suas principais características mas também o contexto europeu e nacional com especial ligação às alterações legislativas no qual se desenvolvem os fluxos migratórios. Destaca-se como Portugal tem sofrido um boom migratório sem precedente apesar do mesmo ser influenciado pela actual crise, levando não só ao declínio da imigração, mas revivendo o fenómeno da emigração.
\end{abstract}

Palavras-chaves: Portugal; Boom migratório; Políticas de imigração; Políticas de integração; Modelo da Europa do Sul.

\section{Introdução}

Os movimentos migratórios são uma das características mais proeminentes das sociedades contemporâneas. A globalização tem contribuído para intensificar estes movimentos devido à compressão do tempo e espaço provocada pela revolução dos transportes e das comunicações. ${ }^{1}$ Actualmente, e mesmo com o aumento da fiscalização e controles migratórios, a taxa mundial de migração não pára de crescer, equivalendo a 3\%, versus 2\% de há

\footnotetext{
Investigadora Senior no Centro de Investigações e Estudos de Sociologia do Instituto Universitário de Lisboa (CIES-IUL), e Professora Convidada na Escola de Sociologia e Políticas Públicas do Instituto Universitário de Lisboa. E-mail: padilla.beatriz@gmail.com. Lisboa/Portugal.

** Investigadora e Doctoranda no Centro de Investigações e Estudos de Sociologia do Instituto Universitário de Lisboa (CIES-IUL). E-mail: aleortizscaglione@gmail.com. Lisboa/Portugal.

1 HARVEY, David. The Condition of Postmodernity.
} 
40 anos atrás. ${ }^{2}$ Desde 2006 que as migrações integram a agenda das Nações Unidas, após decisão tomada por Koffi Annan nesse sentido. Segundo os dados da Organização das Nações Unidas, dos 191 milhões de migrantes no mundo, 34\% vivem na Europa.

Desde uma perspectiva europeia, pode-se afirmar que os movimentos migratórios atravessaram diferentes etapas ao longo do último século: transatlânticos, intra-europeus e finalmente transnacionais. As migrações transatlânticas predominaram na primeira metade do século XX, período no qual milhões de europeus se dirigiram ao continente americano e à Oceania. Após a Segunda Guerra Mundial, a necessidade de reconstrução da Europa apoiada pelo Plano Marshall, fez com que os fluxos migratórios fossem sobretudo intra-europeus. Recorreu-se então a programas de trabalhadores convidados ou guestworkers que incluiu os países da Europa do Sul e de outras regiões como a Turquia e o norte de África, nomeadamente Marrocos. ${ }^{3}$

A primeira crise do petróleo na década de 1970 inaugurou uma nova etapa caracterizada por políticas de restrições migratórias na Europa. Nas décadas seguintes a Europa assistiu a dois processos políticos complexos. Por um lado, à consolidação e alargamento da Comunidade Económica Europeia posteriormente designada por União Europeia, e por outro lado, à queda do muro de Berlim e ao desmembramento da então União Soviética. Ambos os processos implicaram transformações migratórias das sociedades envolvidas, incentivando factores de atracção ou expulsão e revolucionando as sociedades europeias. Enquanto os países da União Europeia precisavam de mão-de-obra, os antigos países socialistas, expulsavam os seus cidadãos. ${ }^{4}$ Entre 1995 e 2005, muitos países europeus aumentaram consideravelmente o stock de imigrantes, fenómeno que se evidencia especialmente nos países Mediterrânicos e da Europa do Sul, quer devido a novas entradas quer a processos de regularização. ${ }^{5}$

Em consequência, nas últimas décadas, as tendências e a direcção dos fluxos migratórios dentro da Europa sofreram mudanças consideráveis, e vários dos países europeus que disponibilizavam mão-de-obra, passaram num espaço curto de tempo, a ser receptores. Esta tendência tem caracterizado especialmente os países do Sul da Europa (Espanha, Grécia, Itália e Portugal) que repentinamente começaram a receber contingentes consideráveis de imigrantes, convertendo-se em países de imigração. Como já foi apontado, a adesão à União

\footnotetext{
BADIE, Bertrand et alii. Pour un autre regard sur les migrations.

CASTLES, Stephen; MILLER, Mark J. The Age of Migration.

Ibidem.

SALT, John. Current Trend on International Migration in Europe.
} 
Europeia (salvo Itália, que já era membro), implicou grandes mudanças. Assistiuse à necessidade de incorporar mão-de -obra qualificada e não qualificada com o objectivo de dar resposta às grandes obras de infra-estruturas resultantes de investimentos públicos e de uma modernização acelerada, ambos processos relacionados com a disponibilidade de fundos europeus. ${ }^{6}$

Embora Portugal se insira no modelo de imigração do sul da Europa, apresenta contudo algumas características distintivas. O modelo do sul da Europa caracteriza-se pela crescente feminização dos fluxos migratórios, por possuir um mercado de trabalho segmentado por questões étnico/raciais, por sexo, pela idade e pelo nível educacional. Outras características envolvem a prevalência da economia informal, o alto crescimento do sector dos serviços e da construção civil e a grande diversidade de países de origem, de estatutos e de nível sócio-económico dos imigrantes. ${ }^{7}$ Outra das particularidades é a distribuição polarizada dos imigrantes no mercado de trabalho, onde se inserem tanto os imigrantes altamente qualificados como os de menor qualificação. Tudo isto indica que o rosto da imigração em Portugal tem mudado paulatinamente, se comparados com os fluxos da década de 1980 e 1990.

Ainda, no que se refere ao modelo português, verifica-se que se bem os fluxos de saída apresentaram altos e baixos nunca cessaram. Pode-se afirmar que a emigração tem sido um fenómeno constante na sociedade portuguesa ao longo do século XX e início do século $X X I^{8}$ pelo que mesmo quando a emigração não se mencione especificamente, devemos estar cientes que existe.

\section{De Portugal emigrante a Portugal imigrante}

Uma correcta interpretação dos movimentos migratórios portugueses actuais só é possível depois de entender a sua história migratória, começando pela emigração. A emigração portuguesa pode ser dividida em fases: a-) a transatlântica (predominantemente para o Brasil) até fim da Segunda Guerra Mundial; b-) primeira vaga intra-europeia a partir da década de 1960 até 1974 (predominantemente para França e Alemanha); c-) segunda vaga europeia após a adesão à União Europeia (destinos não tradicionais e com novas modalidades, i.e. especialmente para a Suíça, a Espanha e Andorra,

6 Ibidem; CASTLES, MILLER, op. cit.; PEIXOTO, João. "New Migrations in Portugal: Labour Markets, Smuggling and Gender Segmentation".

7 BALDWIN-EDWARDS, Martin. "The emerging European immigration regime: some reflections on implications for Southern Europe"; REYNERI, Emilio. "The role of the underground economy in irregular migration toltaly: cause or effect?"; KING, Russell e ZONTINI, Elisabetta. The role of gender in the South European model.

8 BAGANHA, Maria; PEIXOTO, João. "Trends in the 90's: the Portuguese migratory experience"; PIRES, Rui Pena et alii. Portugal. Atlas das Migrações; MARQUES, José Carlos. Os Portugueses na Suíça: Migrantes Europeus. 
com contratos temporários e precariedade nas condições de trabalho); d-) globalização e anti-crise (recentes migrações de trabalhadores qualificados e expatriados, ao Brasil e ex-colónias, e a outros destinos).

A perspectiva transnacional tem contribuído para perceber o fenómeno das migrações duma forma mais ampla. Segundo Marques,

Portugal está inserido num sistema que assume como uma das suas características centrais a multipolaridade de destinos migratórios que vão sendo accionados de acordo com um conjunto de oportunidades que emergem e de desenvolvem nos diferentes quadros nacionais (referindo-se europeus, no entanto acrescentaríamos internacional desde a crise de 2009) e cuja manutenção no tempo se encontra condicionada pela evolução deste mesmo conjunto de oportunidades e/ou pelo surgimento de conjunturas migratórias alternativas. ${ }^{9}$

Dito isto, resulta claro que os movimentos migratórios, especialmente em Portugal, são moldados por uma multiplicidade de factores que devem ser conjugados com o que acontece em várias outras regiões do globo, particularmente naquelas onde os portugueses estiveram presentes quer como colonizadores quer como emigrantes.

Voltando aos movimentos migratórios, uma particularidade portuguesa, se compararmos com os outros países do sul de Europa, diz respeito ao momento que pode ser considerado de viragem entre a emigração e a imigração, marcado pelo fim da guerra colonial e a independência das excolónias portuguesas em África, entre 1974 e 1976. Nessa altura regressaram a Portugal milhares de pessoas que viviam nos territórios ultramarinos, os denominados retornados ${ }^{10}$, influenciando as vagas migratórias seguintes.

QUADRO 1

Recentes Vagas Migratórias Portuguesas, 1950 - presente

Períodos Históricos Recentes de Migração de Portugal, 1950-presente

\begin{tabular}{l|l|l|l}
\hline \multicolumn{1}{c|}{ 1950-1974 } & \multicolumn{1}{c|}{$\mathbf{1 9 7 4 - 1 9 8 6}$} & \multicolumn{1}{c}{$\mathbf{1 9 8 6 - 2 0 0 0}$} & \multicolumn{1}{c}{ Século XXI } \\
\hline 1950-60 emigração & E/imigração & Entrada à CEE & $\begin{array}{l}\text { Imigração intensa e } \\
\text { diversificada }\end{array}$ \\
\hline 1960-74 guerra colonial & Retornados & $\begin{array}{l}\text { Primeiros processos } \\
\text { de regularização }\end{array}$ & Várias regularizações \\
\hline $\begin{array}{l}\text { Chegada de trabalhado- } \\
\text { res de Cabo Verde }\end{array}$ & $\begin{array}{l}\text { Cidadãos PALOPs } \\
\text { perdem a naciona- } \\
\text { lidade portuguesa }\end{array}$ & $\begin{array}{l}\text { Aumento da } \\
\text { imigração }\end{array}$ & Crise: nova emigração \\
\hline
\end{tabular}

Fonte: Adaptado de PADILLA, Beatriz e MATIAS, Raquel. "Migratory and nationality politics in Portugal".

9 Ibidem, p. 225.

${ }^{10}$ PIRES, Rui Pena. Migrações e Integração: Teoria e aplicações à Sociedade Portuguesa. 
A história portuguesa de migração desde o fim da Segunda Guerra Mundial pode ser alargada e resumida no Quadro 1, que constituirá o ponto de partida para a análise que faremos seguidamente. Tomando como ponto de partida a entrada de Portugal em 1986 ao que hoje é a União Europeia, resumiremos as grandes mudanças que se operaram na altura até fim da década de 1990, e pormenorizaremos as mudanças que tiveram lugar durante a primeira década do século XXI.

A adesão de Portugal à então Comunidade Económica Europeia (CEE) inaugurou uma nova etapa que significou grandes mudanças quer nos movimentos migratórios quer nas políticas migratórias do país. A partir de 1986 Portugal converteu-se num país política e economicamente mais atractivo para imigrantes, especialmente depois da assinatura da Convenção Schengen ao criar um espaço de circulação europeu e uma cidadania europeia. ${ }^{11}$ Até esse momento, as maiores comunidades imigrantes em Portugal eram de origem africana, especialmente dos PALOPs (Países Africanos de Língua Oficial Portuguesa). No período de 1975-1980 a população estrangeira passou de 32.000 para 58.000. Em relação a este aumento, Marques refere que:

Para uma compreensão adequada do aumento da população imigrante em Portugal, principalmente da proveniente das excolónias, é necessário salientar que uma parte substancial destes imigrantes só adquiriu a condição jurídica de não nacional de forma retroactiva. Trata-se dos nacionais portugueses de ascendência africana que entraram ou permaneceram em Portugal como cidadãos nacionais e aos quais o Decreto-Lei № 308-A/75, de 24 de Junho, veio substituir a nacionalidade original pela nacionalidade do país de nascimento, ou pela nacionalidade dos pais. $^{12}$

Em 1990, o número de estrangeiros em Portugal era de 100.000, predominando os imigrantes africanos dos PALOPs, como já assinalado. A estes somaram-se os europeus e os brasileiros, respondendo a diferentes necessidades do mercado laboral. Foi ao longo da década de 1990 que os fluxos migratórios se tornaram mais complexos e começaram a divergir dos anteriores, sentando as bases dos fluxos que caracterizariam o início do novo século. ${ }^{13}$ Enquanto que os imigrantes de origem africana, de Cabo Verde, Guiné

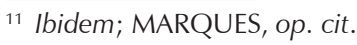

12 Ibidem, p. 233.

${ }^{13}$ BAGANHA, Maria; FERRÃO, João; MALHEIROS, Jorge M. (orgs.). Os Movimentos Migratórios Externos e sua incidência no Mercado de Trabalho em Portugal; MALHEIROS, Jorge Macaísta. "NNew' immigration and regional development: current situation and opportunities for Portuguese regions"; PIRES, Rui Pena. "Mudanças na Imigração: uma análise das estatísticas sobre a população estrangeira em Portugal, 1998/2001". 
Bissau e Angola, se concentravam no mercado de trabalho pouco qualificado, ${ }^{14}$ os europeus ${ }^{15}$ concentraram-se no mercado mais qualificado. Quanto aos brasileiros, verifica-se que se bem no início ocupariam lugares de qualificação alta e intermédia, passaram ao longo da década a ocupar postos de trabalho de menor qualificação, ${ }^{16}$ processo denominado de proletarização. ${ }^{17}$ Neste sentido os brasileiros imigrantes em Portugal foram sempre um grupo atípico por estar representado nas profissões e ocupações de alta, média e baixa qualificação.

Reyneri ${ }^{18}$ diferencia Portugal do resto dos países do sul da Europa ao considerar que a sua situação era mais complexa e paradoxal. Afirma que no momento da entrada à CEE, Portugal precisou tanto de mão-de-obra qualificada como não qualificada, devido ao deficiente sistema educativo português e à emigração para os países da Europa do norte e central dos portugueses menos qualificados. Na prática, a chegada dos profissionais brasileiros no início de 1990 foi absorvida em vários sectores da economia (dentistas, publicistas, especialistas de marketing e informáticos), estendendo-se a outros sectores de menor qualificação. Quanto aos imigrantes dos PALOPs estes vieram a substituir os emigrantes portugueses, concentrando-se no sector da construção civil caracterizado pelas condições de trabalho muito precárias. ${ }^{19}$

Ao longo da década de 1990 os fluxos tornaram-se mais intensos e diversificadostanto na origem como nas ocupações, situação que se consolidaria na primeira década do século XXI. Aos stocks de imigrantes provenientes dos PALOPs e aos brasileiros, vieram juntar-se imigrantes provenientes dos países de Europa de Leste não pertencentes então à União Europeia (ucranianos, romenos, moldavos, russos, entre os mais representativos). Para atenuar o impacto da presença de romenos e búlgaros como trabalhadores e cidadãos europeus, após a adesão da Roménia e a Bulgária em 2007, vários países da UE estabeleceram uma moratória de dois ou mais anos, adiando o exercício dos direitos laborais. Não foi o caso de Portugal, que os reconheceu de forma imediata como europeus de pleno direito, mesmo quando representavam uma das principais comunidades imigrantes.

\footnotetext{
${ }^{14}$ WALL, Karin; NUNES Cátia; MATIAS, Ana R. Female Migration Vision; PIRES, Rui Pena. "A Imigração".

${ }^{15} \mathrm{~A}$ literatura portuguesa denomina imigrantes europeus àqueles provenientes dos países integrantes da União Europeia, pelo que os provenientes do continente europeu que não integra a União, são geralmente chamados de Europa do Leste. Com o alargamento da UE, os cidadãos de alguns países transitaram de europeus do Leste a Europeus (embora ainda existam algumas divergências). O caso mais relevante para Portugal é dos romenos.

${ }^{16}$ PEIXOTO, João. "Strong markets, weak states: the case of recent foreign immigration in Portugal".

17 PADILLA, Beatriz. "Redes sociales de los brasileros recién llegados a Portugal: ¿̇solidaridad étnica o empatía étnica?".

${ }^{18}$ REYNERI, Emilio. "Illegal immigration and the underground economy".

${ }^{19}$ Ibidem; BAGANHA, PEIXOTO, op. cit.; PADILLA, "Redes sociales..., op. cit.
} 
Neste período ainda chegaram imigrantes da Ásia, especialmente da China, Índia e Paquistão e mais tardiamente do Bangladesh. Inicialmente as conexões com a presença portuguesa na Ásia via Macau e em África com a Índia, actuaram como catalisadores. Posteriormente, as redes migratórias e os acordos comerciais com a China, reforçaram os fluxos.

Concordamos assim com Baganha et alii ao afirmarem que a presença de imigrantes em Portugal até final do século XX era "relativamente fraca e a maioria dos movimentos que ocorriam podia atribuir-se directamente ao nosso passado colonial, às nossas relações históricas e culturais, bem como as nossas relações económicas" ${ }^{\prime 20}$. Por isso a evolução dos fluxos migratórios faz com que uma fotografia da imigração no início da década de 1990 seja totalmente diferente a uma fotografia de início do século XXI. A primeira seria caracterizada por imigrantes dos PALOPS, europeus, e brasileiros e a segunda apresentando uma imagem muito diversificada que abrange os grupos migrantes mencionados, acrescentando os fluxos de europeus do leste, e ainda um conjunto de cidadãos oriundos da Ásia, muitos deles comerciantes. ${ }^{21}$

As dinâmicas migratórias são sempre uma resposta a um conjunto de factores tanto nos países de origem como nos de destino, e incluem as políticas e regulamentação das migrações, as redes migratórias informais e os mercados laborais. Em Portugal todos estes factores são relevantes, no entanto Peixoto ${ }^{22}$ salienta que o mercado de trabalho tem desempenhado um papel preponderante, absorvendo imigrantes no mercado de trabalho formal e informal, e contribuindo para a consolidação dos fluxos, que alcançaram até meados da primeira década do século XXI uma taxa anual de crescimento de $7,1 \% .^{23}$

Desde 2009, com o início da crise em Portugal, os fluxos migratórios começaram a sofrer algumas alterações. Por um lado nota-se a desaceleração e a diminuição da imigração, que se reflecte na queda global dos residentes estrangeiros, segundo os dados do Serviço de Estrangeiros e Fronteiras. Por outro lado, verifica-se o retorno ao país de origem, especialmente de brasileiros, como indicam os dados da Organização Internacional das Migrações e alguns estudos. ${ }^{24}$ Do lado da emigração, assiste-se a um crescimento acelerado das saídas de cidadãos portugueses, tanto qualificados como de pouca qualificação, embora a comunicação social ressalte especialmente a saída de recursos humanos qualificados. A criação do Observatório da Emigração em 2008 ilustra a relevância do fenómeno. Segundo os dados desta entidade,

${ }^{20}$ BAGANHA, Maria et alii. "New migrations, new challenges: immigration from Eastern Europe", p. 24.

${ }^{21}$ OLIVEIRA, Catarina. Empresários de Origem Imigrante: Estratégias de Inserção Económica em Portugal.

22 PEIXOTO, "New Migrations..., op. cit.

${ }^{23}$ FONSECA, Maria Lucinda, MALHEIROS, Jorge Macaísta; SILVA, Sandra. "Portugal".

${ }^{24}$ PEIXOTO, João; IORIO, Juliana. Crise, Imigração e Mercado de Trabalho em Portugal. 
a lista de países de proveniência das remessas enviadas pelos portugueses em 2010 estava encabeçada pela França e a Suíça, seguidas de Angola, dos Estados Unidos, da Alemanha e da Espanha.

\section{Notas metodológicas e limitações dos dados nas estatísticas nacionais}

Algumas notas metodológicas são necessárias para uma melhor compreensão dos dados estatísticos sobre a imigração em Portugal. As principais fontes de dados nesta matéria são o Serviço de Estrangeiros e Fronteiras (SEF) e o Instituto Nacional de Estatística (INE).

Existem também outras fontes dentro da Administração Pública, como o Ministério dos Negócios Estrangeiros, o Ministério da Solidariedade e Segurança Social (na sua denominação actual), e a Conservatória dos Registos Centrais, entre outros, que possuem dados relacionados com os imigrantes (vistos concedidos no estrangeiro, cidadãos estrangeiros registados na Segurança Social, naturalizações e aquisição de nacionalidade, etc.).

Em 2007 surge o Sistema Integrado de Informação (SII) do SEF (SIISEF) que usa a base de dados INESEF, a qual resultou dum protocolo entre ambas instituições. Dito protocolo teria como objectivo unificar a informação estatística sobre a população estrangeira em Portugal. Desta base de dados são extraídos os dados sobre os cidadãos estrangeiros que solicitaram algum dos títulos de residência vigentes no país (os quais têm mudado ao longo do tempo, incluindo autorizações de residência, autorizações de permanência, vistos de curta e longa duração, prorrogações dos anteriores, entre outros). Os relatórios estatísticos do SEF encontram-se disponíveis no portal SEFSTAT (http://sefstat.sef.pt).

A partir de 2007 e para efeitos estatísticos,

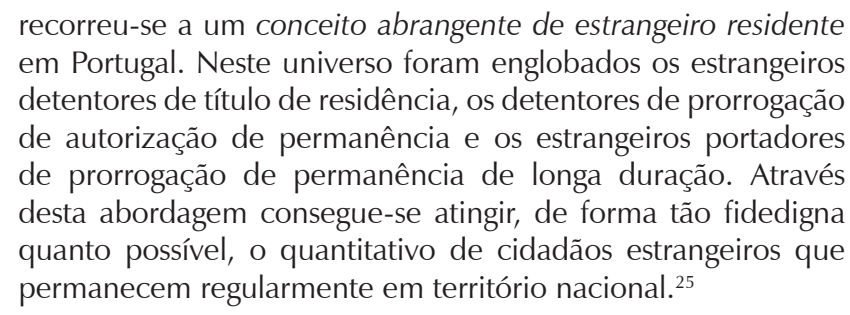

É de salientar que os dados referem-se unicamente a estrangeiros legalizados, ficando sempre excluídos os imigrantes que não possuem títulos de residência. Neste sentido, os estrangeiros que não conseguem renovar o título legal de residência, os que adquiriram a nacionalidade e aqueles que mesmo residindo no país nunca tiveram um título legal, ficam sempre

${ }^{25}$ SEF. Relatório de actividades, 2007, p. 7. 
excluídos das estatísticas oficiais. Os recenseamentos da população realizados durante os Censos Nacionais de 10 em 10 ano, registam todos os residentes independentemente do seu estatuto legal. Lamentavelmente os dados do Censo de 2011 ainda não se encontram disponíveis.

Conhecer as diferentes formas de contabilizar os imigrantes torna-se importante quando se realizam estudos comparados já que outros países europeus possuem dados mais abrangentes. Espanha, por exemplo, conta com um sistema universal de "empadronamiento" a nível municipal que permite que todos os registados usufruam dos serviços públicos independentemente da sua condição.

Os dois aspectos mais complexos na apreciação dos dados estatísticos de imigração em Portugal referem-se à existência de diversos tipos de títulos de residência ao longo do tempo, e à descontinuidade de algumas variáveis importantes que ajudavam a caracterizar a imigração tais como a situação na profissão e o nível de habilitações. Ainda, outro aspecto que gera também ambiguidade sobre os imigrantes provenientes de países terceiros (não membros da UE) é que os dados não recolhem informação sobre a naturalidade, usando a nacionalidade como único critério de referência, assistindo-se assim a uma sub-contabilização daqueles com dupla nacionalidade. O exemplo mais representativo é o dos brasileiros, e outros cidadãos latino-americanos, que nas estatísticas aparecem designados como italianos, espanhóis e portugueses.

Os dados disponíveis relativos à aquisição da nacionalidade portuguesa (naturalização, aquisição e atribuição) são pouco precisos, pelo que ainda persistem lacunas na informação. A nível europeu, a fonte de dados mais relevante sobre imigração e fenómenos relacionados é a EUROSTAT, sendo o INE a entidade responsável pelo fornecimento dos dados.

\section{Imigração e Políticas Migratórias}

Existe uma íntima relação e conexão entre os fluxos migratórios e a sua regulação. Já ressaltámos, citando Peixoto ${ }^{26}$ a importância do mercado de trabalho como elemento chave catalisador. No entanto o papel do Estado não pode ser menosprezado. Mesmo que em Portugal grande parte da legislação seja reactiva e não proactiva, ou seja, dê-se como consequência do fenómeno e não como previsão ou antecipação aos movimentos migratórios, a regulamentação em matéria migratória é de destacar, especialmente no período em análise, a partir da década de 1990. A adesão de Portugal à União Europeia implicou mudanças a nível da produção legislativa no âmbito

${ }^{26}$ PEIXOTO, “New Migrations..., op. cit. 
das migrações, nomeadamente um aumento paulatino da regulamentação para se adequar tanto às novas necessidades do mercado de trabalho como às directivas europeias.

O controlo dos fluxos (entrada, permanência, saída, expulsão) é geralmente feito por via das denominadas Leis de Imigração. O Estado Português tem recorrido contudo a decretos e regulamentação extraordinária que deram origem a processos ou mecanismos de legalização ou regularização, os quais contribuíram significativamente para o aumento da população imigrante. Ainda a legislação sobre a nacionalidade também tem sido alterada algumas vezes, estabelecendo quem tem direito a ser português. O conjunto destas normas dá origem ao regime de imigração português.

A principal tendência ao longo do tempo tem sido o aumento do controlo sobre a entrada em Portugal, legislando sobre os tipos de vistos e autorizações de residência, aumentando as penalizações à imigração irregular e ao tráfico, por outras palavras, verifica-se uma crescente criminalização associada aos movimentos de pessoas e uma crescente europeização das políticas e legislação. Desde 1986, em Portugal foram elaboradas 7 leis e 5 decretos-lei, para além dos respectivos decretos regulamentários (quer em matéria de imigração quer de acesso à nacionalidade). Apesar destas medidas, o controlo sobre a entrada dos fluxos migratórios não tem tido sucesso já que desde a essa data, foram aprovados 6 mecanismos de regularização (1992, 1996, 2001, 2003/4, 2005, 2007). A seguinte tabela sintetiza informação sobre os processos de regularização.

\section{QUADRO 2}

Processos e programas de legalização em Portugal desde 1992

\begin{tabular}{|c|c|c|}
\hline Processo & № Legalizados & Características \\
\hline 1992-1993 & 16.000 & $\begin{array}{l}\text { De } 39.000 \text { pedidos, maioria cabo- } \\
\text { verdianos e angolanos }\end{array}$ \\
\hline 1996 & 30.000 & $\begin{array}{l}35.000 \text { pedidos, maioria oriundos dos } \\
\text { PALOPS }\end{array}$ \\
\hline $\begin{array}{l}2001 \text { (Autorizações de Per- } \\
\text { manência) }\end{array}$ & 183.333 & $\begin{array}{l}\text { Europeus de Leste, brasileiros, PALOPS, } \\
\text { outros }\end{array}$ \\
\hline 2003 (Acordo Lula) & $\begin{array}{l}13.998 \text { (Vistos Min. } \\
\text { Negócios Estrangeiros) }\end{array}$ & $\begin{array}{l}\text { Brasileiros: } 30.000 \text { pedidos; } 16.173 \\
\text { prorrogações }\end{array}$ \\
\hline 2004/5 (Processo dos CTT) & & 50.196 registados; 3.019 prorrogações \\
\hline $\begin{array}{l}2007 \text { (ao abrigo do art. } 88 \\
\text { da Lei 23/2007) }\end{array}$ & \begin{tabular}{|l|} 
Indeterminado (taxa de \\
crescimento de pedidos \\
aumentou $27 \%$ em 2008)
\end{tabular} & $\begin{array}{l}\text { Brasileiros, Cabo Verde, Roménia, } \\
\text { Ucrânia, Moldávia, Guiné Bissau, } \\
\text { Angola. }\end{array}$ \\
\hline
\end{tabular}

Fonte: Adaptação de PADILLA, Beatriz. "Acordos bilaterais e legalização: o impacto na integração dos imigrantes brasileiros em Portugal". 
Recentemente, em Setembro de 2012, entrou em vigor a lei 29/2012, que vem alterar o diploma anterior de 2007, tendo como principal objectivo a transposição de várias directivas europeias, entre as quais salientamos a Directiva de Retorno, a do cartão azul que promove a imigração qualificada, a da penalização aos empregadores que contratem imigrantes irregulares introduzindo ainda a penalização dos casamentos por conveniência.

\section{A imigração recente em Portugal}

Como foi mencionado, a imigração é relativamente recente em Portugal. O fenómeno migratório que começou timidamente na década de 1980, progrediu paulatinamente na década de 1990 até se transformar radicalmente na primeira década do século XXI, tanto em termos de intensidade como da composição dos fluxos. A figura 1 ilustra a evolução da população estrangeira residente em Portugal desde 1960, mostrando um crescimento constante a partir da década de 1980, triplicando nas últimas três décadas. Estes dados apresentam algumas omissões nomeadamente aos valores para os anos 1969 e 1973 e a ausência de registos das Autorizações de Permanência (APs) de 2001-2005, concedidas aos estrangeiros ao abrigo dos processos de regularização extraordinária realizados no ano 2001.

\section{FIGURA 1}

\section{Evolução da população estrangeira em Portugal (1960-2011)}

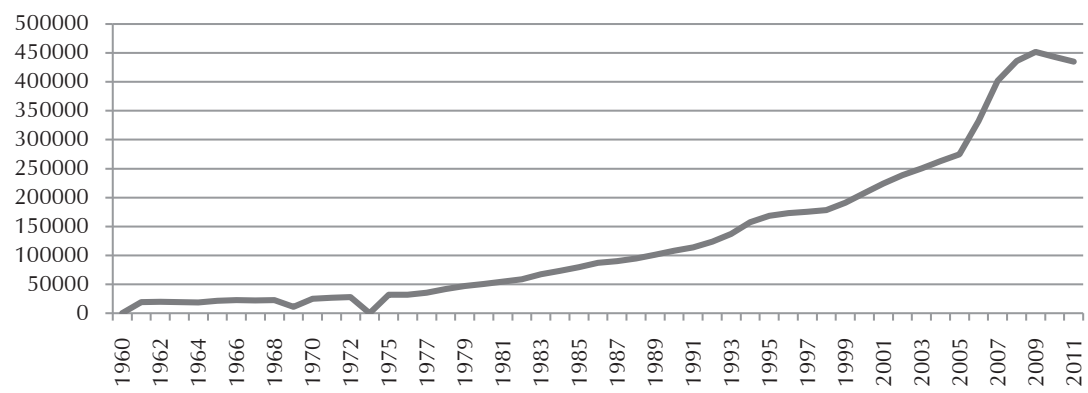

Fonte: INE (Censos e Estatísticas Demográficas) e SEF.

A figura 2 ilustra dita evolução desde 1980 até à actualidade juntamente com a taxa de crescimento da imigração, indicando que durante esse período, o maior crescimento registou-se precisamente entre os anos 2006 e 2007 (21\%), momento no qual muitas das autorizações de permanência foram renovadas como autorizações de residência. Um segundo momento de crescimento registou-se em 1993 e 1994 resultante do processo de regularização de 1992/93. Observese que desde 1980 a primeira vez que a taxa de crescimento da população estrangeira apresentou um valor negativo foi em 2010, repetindo-se em 2011. 
FIGURA 2

Crescimento da população estrangeira em Portugal (1960-2011)

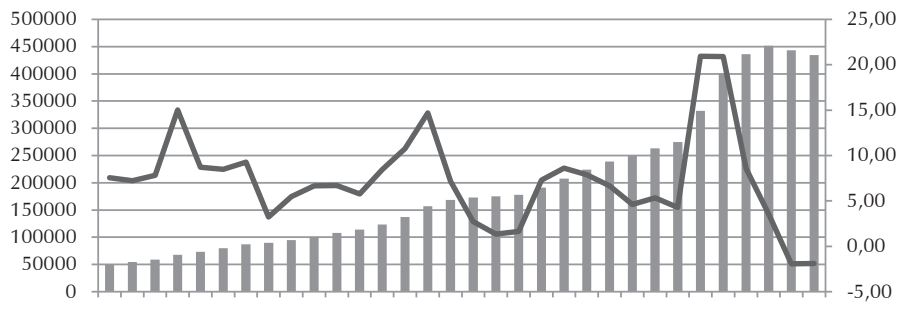

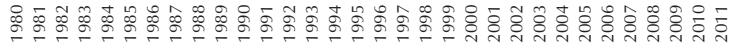

Evolução da população estrangeira Crescimento \%

Fonte: INE (Censos e Estatísticas Demográficas) e SEF.

Ao introduzir as autorizações de permanência (APs) e os Vistos de Longa Duração (VL's) em vigor entre 2001 e 2005 a tendência crescente dos fluxos migratórios torna-se mais evidente, como ilustram a Figura 3. Estes títulos foram consequência dos processos de regularização extraordinários, como já explicado anteriormente. Embora actualmente tenham desaparecido, significaram um salto significativo no crescimento da população estrangeira em Portugal, particularmente a partir do ano 2001, embora com títulos precários. Muitas das autorizações de permanência (que eram renovadas anualmente, até ao máximo de 5 anos) converteram-se em autorizações de residência, transformando-se em títulos que conferiam mais direitos. As autorizações de permanências (APs) outorgadas no processo de regularização extraordinário produziram um crescimento da população estrangeira de $69 \%$ face ao ano anterior, ilustrando um crescimento exponencial.

FIGURA 3

Evolução da população estrangeira incluindo AP's e VL's (1980-2011)

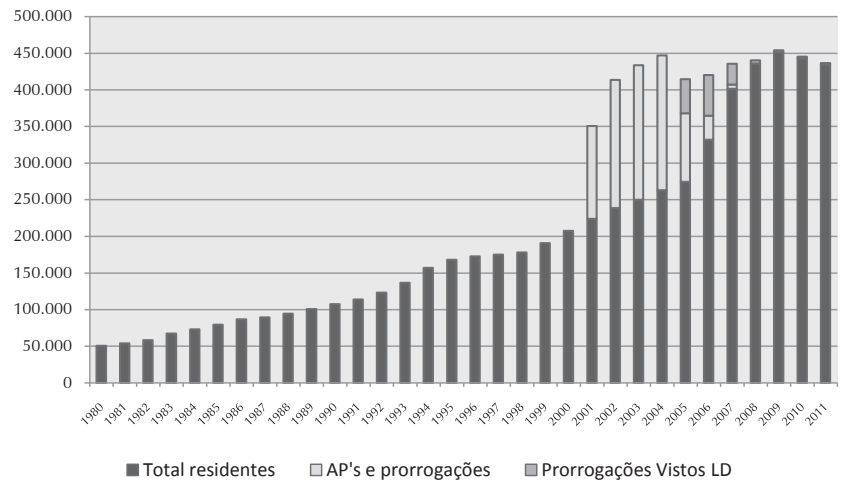

Fonte: INE (Censos e Estatísticas Demográficas) e SEF. 
Relativamente à evolução da população estrangeira tendo em conta o continente de origem, verifica-se uma prevalência até 1980 do continente europeu, especialmente da Europa Ocidental. A partir dos anos 90, o continente africano passa a ser o mais representativo e no início do século XXI soma-se o continente americano, basicamente representado pelo Brasil. Actualmente o continente europeu é ainda um dos mais representados, embora tenha mudado a sua composição ao incluir os nacionais de países da Europa do Leste. Destes sobressaem os ucranianos e romenos, que em conjunto atingem $20 \%$ da população estrangeira residente em Portugal. A Ásia perfila-se como um novo continente de origem em crescimento e com uma presença diversificada de nacionalidades que incluem países como a China, a Índia, o Paquistão e o Bangladesh. A Figura 4 é ilustrativa das tendências.

FIGURA 4

\section{Evolução da população estrangeira por continente (1980-2011)}

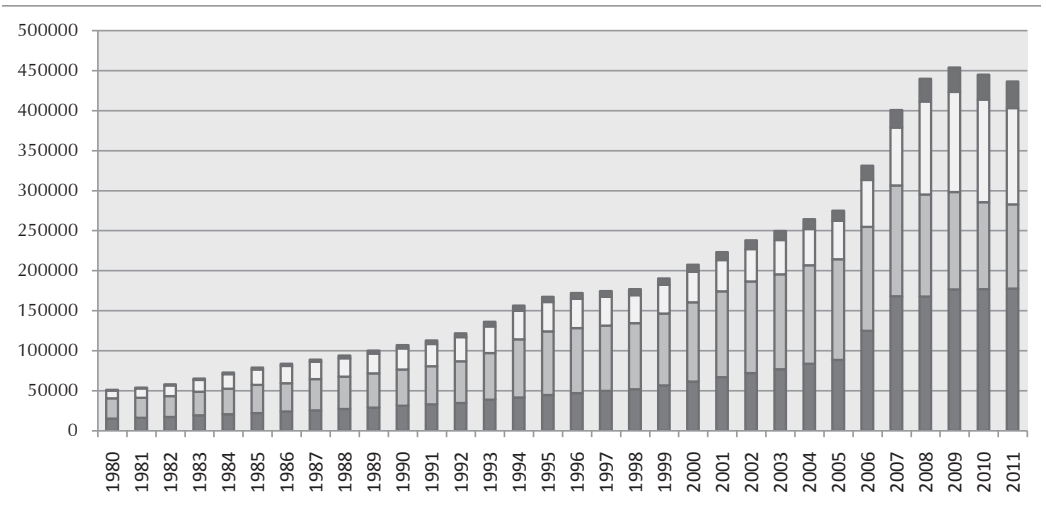

घuropa $\square$ África $\square$ América $\square$ Ásia

Fonte: INE (Censos e Estatísticas Demográficas) e SEF.

Uma análise histórica da evolução das nacionalidades indica que até à década de 1980 os estrangeiros em Portugal eram principalmente europeus do Reino Unido, da França, da Alemanha e da Espanha, hoje membros da União Europeia, conjuntamente com alguns imigrantes de origem brasileira e cabo-verdiana. A partir da década de 1980, o número de imigrantes de origem africana (predominantemente PALOP, Cabo Verde, Guine Bissau e Angola) e de origem brasileira, começa a crescer significativamente e de forma constante até à actualidade. A partir do século XXI, as nacionalidades mais representativas são os ucranianos (legalizados no processo de 2001), 
os cabo-verdianos e os brasileiros. O Brasil torna-se a nacionalidade mais expressiva a partir de 2007.

Um dos fluxos migratórios que veio modificar os padrões anteriormente registrados em Portugal é o denominado caso dos imigrantes de Europa de Leste, verificado no início do milénio e caracterizado pela sua intensidade e concentração temporal em poucos anos. Segundo Baganha et aliii ${ }^{27}$, este fenómeno foi de alguma forma imprevisível já que Portugal não adoptou nenhuma política concreta com esses países, nem tinha qualquer tipo de laço histórico, cultural ou económico com aquela região. Vale contudo a pena salientar que também outros países da União Europeia, tais como Espanha e Italia, passaram por um um processo semelhante ao portugues quanto à chegada dos cidadãos do ex-bloco socialista sem que existissem laços prévios.

Os nacionais daqueles países da Europa de Leste só ganharam visibilidade estatística após o processo de regularização de 2001 (desenvolvido entre 2001 e 2004). Entre as nacionalidades deste conjunto de países destacamse a ucraniana, moldava, romena, a russa e a búlgara, na altura todos países externos à União Europeia, situação que se modificou posteriormente.

\section{TABELA 1}

Principais nacionalidades com APs, concedidas entre 2001-2004

\begin{tabular}{|c|c|c|c|}
\hline País e ordem ranking & № APs & País e ordem ranking & № APs \\
\hline Angola (7) & 8.562 & Paquistão (12) & 2.854 \\
\hline Brasil (2) & 37.951 & Roménia (4) & 10.944 \\
\hline Bulgária (11) & 2.849 & Rússia (8) & 7.053 \\
\hline Cabo Verde (5) & 8.574 & São Tomé e P. (13) & 2.555 \\
\hline China (9) & 3.909 & Ucrânia (1) & 6.4730 \\
\hline Guiné Bissau (6) & 4.323 & Subtotal & 166.017 \\
\hline Índia (10) & 3.389 & Outros & 1.7816 \\
\hline Moldávia (3) & 12.647 & TOTAL & 18.3833 \\
\hline
\end{tabular}

Fonte: SEF (elaboração própria).

O processo de regularização de 2001, através de Autorizações de Permanência (APs), veio consolidar a diversificação do panorama migratório português. Por um lado significou a continuidade dos fluxos lusófonos (PALOPs e Brasil) e por outro lado normalizou a presença de estrangeiros de outras origens, quer os cidadãos dos países da Europa de Leste, quer os cidadãos da Ásia, entre os quais a China, a Índia e o Paquistão. Os dados

${ }^{27}$ BAGANHA, Maria; MARQUES, José Carlos e GÓIS, Pedro. "Imigrantes em Portugal: uma síntese histórica". 
do Serviço de Estrangeiros e Fronteiras correspondentes às autorizações de permanência concedidas ao abrigo do Decreto-Lei 4/2001 indicam que entre 2001 e 2004 foram outorgados 183.833 títulos. Destes, 90\% distribuíram-se por 13 nacionalidades principais, sendo que 56\% dos títulos concentraram-se em duas nacionalidades: a ucraniana e a brasileira. A Tabela 1, com dados relativos às Autorizações de Permanência concedidas entre 2001 e 2004, é ilustrativa.

Ao longo das últimas décadas as principais nacionalidades estrangeiras em Portugal têm vindo a mudar. Se bem ao longo do tempo, os cidadãos cabo-verdianos ocuparam sempre um lugar de destaque, ao longo da primeira década do século XXI, tanto os brasileiros como os ucranianos cresceram de forma significativa. O processo de conversão das Autorizações de Permanência (APs) em Autorizações de Residência (ARs) permitiu a verificar o salto quantitativo provocado maioritariamente pelos ucranianos e outros cidadãos da Europa do Leste. O caso dos brasileiros é mais complexo já que, para além dos títulos conseguidos ao abrigo da regularização de 2001, beneficiaram em 2003 de um processo unicamente para brasileiros, conhecido como do Acordo Lula ${ }^{28}$. Em resumo, o fluxo de brasileiros tem crescido a ritmo constante, passando de 5.000 indivíduos em 1980 a 115.400 em 2011, sendo desde 2007 a nacionalidade estrangeira mais expressiva, que corresponde actualmente a 25,5\% dos estrangeiros residentes.

A tendência crescente dos fluxos será ainda mais evidente a partir de 2007 com a aprovação da Lei de Imigração 23/2007 que previu um mecanismo de regularização em aberto. A entrada em vigor desta lei explica o aumento dos estrangeiros a residir legalmente no país até 2010, momento a partir do qual os efeitos da crise se tornaram mais evidentes e os fluxos começaram a declinar.

O Quadro 2 apresenta as principais nacionalidades estrangeiras em diferentes momentos, ilustrando, precisamente a referida diversificação dos fluxos migratórios ao longo das últimas décadas. Por um lado os fluxos lusófonos (ex-colónias e Brasil) consolidam-se, posicionando-se de forma contínua entre as principais nacionalidades estrangeiras. Por outro lado, surgem os cidadãos da Europa de Leste, com destaque para Ucrânia, Roménia e Moldávia entre as nacionalidades mais expressivas, ocupando nos últimos anos as primeiras posições. A China perfila-se também como uma nacionalidade de relevo.

${ }^{28}$ PADILLA, Beatriz. "Acordos bilaterais e legalização: o impacto na integração dos imigrantes brasileiros em Portugal". 


\section{QUADRO 2}

Evolução das principais nacionalidades estrangeiras em Portugal

\begin{tabular}{c|c|c|c}
\hline $\mathbf{1 9 9 6}$ & $\mathbf{2 0 0 1}$ & $\mathbf{2 0 0 6}$ & $\mathbf{2 0 1 1}$ \\
\hline & Cabo Verde & Cabo Verde & Brasil \\
Cabo Verde & Brasil & Brasil & Ucrânia \\
Brasil & Angola & Ucrânia & Cabo Verde \\
Angola & Guiné-Bissau & Angola & Roménia \\
Guiné-Bissau & Reino Unido & Guiné-Bissau & Angola \\
Reino Unido & Espanha & Reino Unido & Guiné-Bissau \\
& Alemanha & Espanha & Reino Unido \\
& USA & Moldávia & China \\
& França & São Tomé e Príncipe & Moldávia \\
& São Tomé e Príncipe & Roménia & São Tomé e Príncipe \\
\hline
\end{tabular}

$\mathrm{Na}$ actualidade e segundo os últimos dados provisórios ${ }^{29}$ do SEF para o ano 2011, residiam legalmente em Portugal 434.708 estrangeiros, o que corresponde a $4,2 \%$ da população residente em território nacional, apresentando um decréscimo relativamente ao ano anterior de cerca $2 \%$, à semelhança do sucedido em 2010. As nacionalidades mais expressivas resumidas no Quadro 3 são a brasileira, a ucraniana, a cabo-verdiana, a romena e a angolana.

\section{QUADRO 3}

Principais nacionalidades estrangeiras em 2011

\begin{tabular}{l|c|c|c|c}
\hline Nacionalidade & Total & $\%$ & Homens & Mulheres \\
\hline Total nacional & 436.822 & 100 & 219.137 & 217.685 \\
\hline Brasil & 111.445 & 25.5 & 47.518 & 63.927 \\
\hline Ucrânia & 48.022 & 11.0 & 25.883 & 22.139 \\
\hline Cabo Verde & 43.920 & 10.1 & 20.800 & 22.848 \\
\hline Roménia & 39.312 & 9.0 & 22.441 & 16.871 \\
\hline Angola & 21.563 & 4.9 & 10.331 & 11.232 \\
\hline Guiné-Bissau & 18.487 & 4.2 & 10.530 & 7.957 \\
\hline Reino Unido & 17.675 & 4.0 & 9.121 & 8.554 \\
\hline China & 16.785 & 3.8 & 8.648 & 8.137 \\
\hline Moldávia & 13.586 & 3.1 & 7.072 & 6.514 \\
\hline S. Tomé e Príncipe & 10.518 & 2.4 & 4.823 & 5.695 \\
\hline
\end{tabular}

Fonte: INE, Estatísticas Demográficas e SEF.

Quanto à distribuição por género, a imigração em Portugal tem apresentado ao longo do tempo uma masculinização, embora esta tendência tenha sido atenuada nos últimos anos, particularmente no seio de algumas

\footnotetext{
${ }^{29}$ Dados do Relatório de Imigração Fronteiras e Asilo do Serviço de Estrangeiros e Fronteiras, SEF, 2011.
} 
comunidades migrantes em processos de sedentarização, nomeadamente nas comunidades brasileiras e algumas do PALOPS (Cabo Verde, Angola, São Tomé a Príncipe). No geral, os processos de feminização das migrações estão intimamente relacionados com a reunificação familiar, que se verificou em grande medida e ao longo do tempo em quase todas as comunidades de imigrantes em Portugal.

A feminização pode ser também causada pela evolução do mercado de trabalho segmentado segundo a raça/etnicidade e o sexo, criando desta forma alguns nichos laborais específicos, como o dos serviços pessoais, domésticos e das limpezas, fenómeno comum tanto em Portugal como em outros países da União Europeia. Neste sentido a indústria dos cuidados, como tem sido denominado de forma abrangente este sector, tem-se desenvolvido devido ao aumento da demanda de serviços de atenção especializada a pessoas idosas e crianças, somado ao crescimento do sector das limpezas industriais e domésticas. ${ }^{30}$

Quanto à distribuição geográfica, a Figura 5 permite avaliar em que distritos a imigração se concentra. Neste sentido, a Área Metropolitana de Lisboa concentra mais de $50 \%$ dos imigrantes. A população estrangeira distribui-se principalmente pelos distritos de Lisboa, Setúbal, Faro e Porto. A distribuição revela um padrão caracterizado por uma forte concentração nas áreas metropolitanas portuguesas (Lisboa e Porto) e ao longo do litoral do país de norte ao sul, onde se destacam os distritos litorais de Aveiro, Coimbra, Braga e Faro e os das Regiões Autónomas dos Açores e da Madeira. ${ }^{31}$

Relativamente ao interior do país, a Figura 5 também sugere que a presença de imigrantes é pouco expressiva, embora nos últimos anos, se tenha verificado um aumento da população estrangeira em algumas regiões, com destaque para o Alentejo e a Beira Interior onde muitos ucranianos e romenos se instalaram. ${ }^{32}$ Concretamente no referente à distribuição geográfica e às principais nacionalidades, verificam-se padrões espaciais diferentes. Enquanto que os imigrantes provenientes dos PALOPs apresentam uma forte metropolitanização, concentrando-se nas áreas urbanas metropolitanas de Lisboa e Porto, particularmente na primeira, os brasileiros apresentam uma distribuição mais dispersa (menos concentrada) por todo o território nacional. Por último, os imigrantes da Europa de Leste apresentam um padrão espacial ainda mais disperso, com um peso superior face às outras comunidades no

\footnotetext{
${ }^{30}$ WALL et alii, op. cit.; MIRANDA, Joana. Mulheres imigrantes em Portugal: memórias, dificuldades de Integração e projectos de vida.

${ }^{31}$ FONSECA, Maria Lucinda. "Territorial Insertion - urban planning, Regional Development and local atraction policies".

32 Ibidem.
} 
Ribatejo, no Alentejo e na Região Oeste. ${ }^{33} \mathrm{Na}$ generalidade a maioria dos imigrantes residem nos centros urbanos do país.

\section{FIGURA 5}

\section{Distribuição Geográfica da População Imigrante em Portugal, 2011}

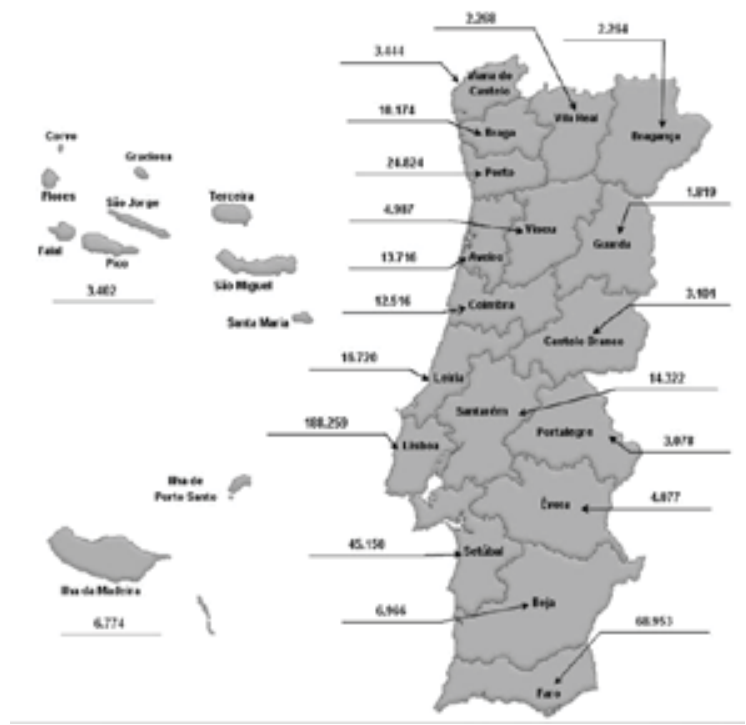

Fonte: SEF, 2011.

Outro fenómeno intimamente relacionado com as migrações é o acesso à nacionalidade. Como foi explicado na secção das políticas, as mudanças na legislação que regula a aquisição da nacionalidade impacta directamente no número de estrangeiros que passam a ser cidadãos portugueses (ver Figura 6). Como tal, as mudanças adoptadas nas últimas décadas têm vindo a facilitar paulatinamente o acesso à nacionalidade portuguesa, o que em termos estatísticos significa que quem adquire a nacionalidade portuguesa deixa de ser contabilizado como estrangeiro. O acesso à nacionalidade portuguesa significa também o acesso à cidadania europeia, o que facilita a mobilidade dentro da União Europeia.

Os últimos dados disponibilizados pelo INE ao EUROSTAT mostram que em 2009, 25.500 residentes estrangeiros adquiriram a nacionalidade portuguesa. Esta tendência é significativamente superior à da década anterior, que apresentava uma média anual de 2000 concessões. Já entre 2000 e 2006 a média das aquisições subiu ligeiramente para 2.500. Segundo os dados do EUROSTAT, actualmente Portugal é o país com a taxa de naturalização mais elevada da União Europeia.

\footnotetext{
33 Ibidem.
} 
Pode-se destacar que do total de aquisições em 2009, as principais nacionalidades foram a cabo-verdiana, a brasileira, a moldava, a guinnense, a angolana, a santomense, a ucraniana e a indiana. Contudo sabe-se que os ucranianos só recentemente optaram pela aquisição da nacionalidade portuguesa devido a que a Ucrânia proibia expressamente a dupla nacionalidade. ${ }^{34}$

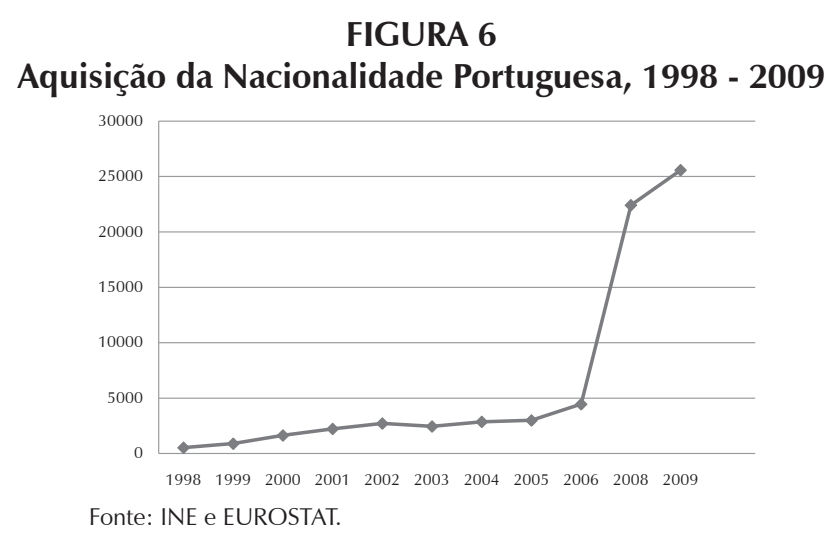

\section{Principais características sócio-demográficas da população imigrante em Portugal}

Uma análise transversal dos dados sobre a população imigrante em Portugal (SEF, INE) que consideram os movimentos de população, os nascimentos e casamentos e as qualificações, permite esboçar algumas generalizações sobre as principais características sócio-demográficas dos imigrantes que residem no país, em comparação com a população portuguesa. Estas generalizações aparecem resumidas no Quadro 4.

\section{QUADRO 4}

\section{Características Sócio-demográficas dos imigrantes}

\begin{tabular}{l|l}
\hline Características & Descrição \\
\hline $\begin{array}{l}\text { Idade - rejuve- } \\
\text { nescimento }\end{array}$ & $\begin{array}{l}\text { Os imigrantes são jovens, em idade produtiva e economicamente activos, } \\
\text { contrapesando parcialmente o envelhecimento da população nacional }\end{array}$ \\
\hline $\begin{array}{l}\text { Distribuição } \\
\text { geográfica }\end{array}$ & $\begin{array}{l}\text { Localização urbana nas e à volta das cidades, preferentemente na zona litoral e } \\
\text { áreas metropolitanas }\end{array}$ \\
\hline Casamentos & $\begin{array}{l}\text { Aumento dos casamentos mistos (um cônjuge estrangeiro) face à quebra dos } \\
\text { casamentos entre portugueses e o aumento dos divórcios. Entre 2001 e 2007 } \\
\text { os casamentos mistos aumentaram 3,8\%, representando no ano 2007, 21\% do } \\
\text { total de casamentos }{ }^{(1)} \text {. }\end{array}$ \\
\hline
\end{tabular}

${ }^{34}$ PADILLA, Beatriz; ORTIZ, Alejandra "O acesso a nacionalidade como instrumento chave da cidadania. Barreiras e gaps que ainda persistem". 


\begin{tabular}{l|l}
\hline Natalidade & $\begin{array}{l}\text { O nascimento de crianças de mães estrangeiras duplicou entre 2001 e 2009, } \\
\text { sendo que nesse ultimo ano correspondia a 10,4\% do total. As famílias de } \\
\text { imigrantes são mais numerosas }\end{array}$ \\
\hline $\begin{array}{l}\text { Mercado de } \\
\text { trabalho }\end{array}$ & $\begin{array}{l}\text { Bipolarização } \\
\text { qualificados } \text { marcada pela concentração dos imigrantes nos sectores menos } \\
\text { dos serviços (brasileiros, Europa do Leste), e no sector qualificado (cidadãos da } \\
\text { UE, brasileiros da primeira vaga).Proletarização paulatina da imigração }\end{array}$ \\
\hline Irregularidade & $\begin{array}{l}\text { Os subsequentes processos de legalização e regularização são um indicativo } \\
\text { da persistente presença de imigrantes irregulares, tanto os recém-chegados ao } \\
\text { carecerem de títulos de residência válidos, como por não conseguir renová-los } \\
\text { por falta de um contrato de trabalho que permite a renovação. Em consequên- } \\
\text { cia existe um círculo vicioso da irregularidade. }\end{array}$ \\
\hline
\end{tabular}

Fonte: Elaboração própria.

${ }^{1}$ RAMOS Madalena; FERREIRA Ana Cristina. "Marriage with Immigrants in Portugal, Global Perspectives on Marriage and International Migration".

${ }^{2}$ PEIXOTO, New Migrations..., op. cit.; BAGANHA, Maria et alii. "New migrations..., op. cit.

${ }^{3}$ PADILLA, Beatriz. "Acordos bilaterais e legalização: o impacto na integração dos imigrantes brasileiros em Portugal".

\section{Conjuntura actual: tendências "latentes"}

O último fenómeno registado e derivado da actual crise é o retorno dos imigrantes aos seus países de origem. Convém contudo ter em conta que nem todos os imigrantes têm previsto o seu regresso, já que muitos pretendem ficar, na medida em que consigam superar a presente situação. Como é do conhecimento geral, o clima económico-financeiro em Portugal tem piorado desde o início do "resgate financeiro" em mediados de 2011, conhecido como Troika, por contar com a representação de três instituições, o Fundo Monetário Internacional, o Banco Central Europeu e a Comissão Europeia, que tem imposto medidas de austeridade extrema.

Devido à falta de recursos para fazer frente aos compromissos internacionais, a situação portuguesa encontra-se marcada por um crescente desemprego, pela redução dos salários e pelo aumento dos impostos.

Nesta conjuntura, os imigrantes têm sido mais prejudicados que os nacionais, já que a taxa de desemprego dos imigrantes é bastante mais elevada que a dos portugueses. O carácter global e sobretudo europeu da crise não tem promovido muitas migrações dentro da Europa, salvo aos países menos afectados como Alemanha ou o Reino Unido, já que a maioria dos estados da região vivem condições semelhantes. Por outro lado, como os imigrantes têm menos direitos adquiridos, a necessidade de retornar tem-se acentuado, ao mesmo tempo que as condições de alguns países de origem têm mostrado melhorias, nomeadamente Angola e o Brasil. 


\section{Notas conclusivas}

Os movimentos migratórios de emigração e imigração têm sido uma constante em Portugal, persistindo com altos e baixos ambos fenómenos em simultâneo até ao presente.

Pensando na imigração, desde os finais da década de 1990, a principal característica tem sido a crescente europeização dos marcos legais. Ditos marcos têm contribuído paulatinamente para a restrição da liberdade de acção dos países membros da UE. Apesar disso podemos identificar alguma flexibilidade nas medidas portuguesas.

Por um lado, a europeização traduz-se no factor ou motor das mudanças legislativas que são consequência da transposição de directivas da UE à legislação nacional (i.e. reunificação familiar, retorno, imigração qualificada, estudantes internacionais, asilo, etc.). Por outro lado, ultrapassando a europeização, a influência da globalização também tem modelado alguns aspectos da imigração em Portugal, tal como o demonstra a persistente irregularidade que caracteriza os fluxos, ${ }^{35}$ a crescente segmentação do mercado de trabalho, e a criminalização. A partir de 2001 a criminalização torna-se mais evidente devido aos ataques terroristas nos Estados Unidos. Consequentemente, a legislação europeia e portuguesa têm-se tornado mais controladora, criminalizadora e penalizadora.

No pólo oposto, alguns elementos da influência portuguesa tem sido sui generis, contrapesando à criminalização e apostando, na medida do possível, na vertente da incorporação dos imigrantes à sociedade de acolhimento. Dita aposta visa melhorar também a posição e reconhecimento internacional de Portugal, tal como mostrado na liderança de iniciativas de integração a nível europeu nas diferentes esferas, especialmente durante a Presidência Portuguesa do Conselho da União Europeia em 2007. ${ }^{36}$ Tal tendência é analisada no MIPEX (Migration Integration Policy Índex, ou índice de políticas de integração de imigrantes na versão portuguesa), elaborada pelo Migration Policy Group e patrocinado pelo British Council (http://www.mipex.eu/), no qual Portugal é classificado segundo melhor.

Se até 2009 os fluxos migratórios tiveram uma tendência crescente, em 2010 e em 2011 a tendência reverte-se. No entanto, o balanço dos fluxos migratórios do último decénio mostra-se positivo, já que a sociedade portuguesa assistiu a um aumento considerável da diversidade étnica/racial,

\footnotetext{
${ }^{35}$ SASSEN, Saskia, Guests and aliens.

${ }^{36}$ FERNANDES Ana; PEREIRA José Miguel. Health and Migration in the Euroepan Union: Better Health for all in an inclusive society.
} 
religiosa, económica e cultural, tal como vários estudos apontam. ${ }^{37}$ Ao longo da primeira década do século XXI, aos fluxos migratórios tradicionais, dominados pelos imigrantes das ex-colónias portuguesas em África e do Brasil que ainda mantêm-se activos, somaram-se outros fluxos que vieram diversificar de forma significativa a sua composição. Esta diversificação, impensável a meados da década de 1990, engloba diversas nacionalidades provenientes de países da Europa de Leste (Ucrânia, Roménia, Moldávia, Rússia, Bulgária) e da Ásia (China, Índia, Paquistão, e mais recentemente Bangladesh). Outra consequência do boom migratório tem sido o aumento dos nascimentos e casamentos, bem como um certo rejuvenescimento da população em idade activa, fenómenos positivos face ao envelhecimento da população nacional, ainda que não sejam suficiente para alterar a tendência.

No geral, as respostas de Portugal aos desafios da imigração, tal como mencionado, têm sido harmonizadoras, conciliando as necessidades do mercado de trabalho nacional com as exigências europeias. No contexto europeu de crescente criminalização, a visão portuguesa até agora tem sido mais humanitária, mesmo implementando as restrições que chegam por exigências europeias (deportações, expulsões, maior controle dos fluxos). Como Acosta ${ }^{38}$ sugeriu, Portugal está entre os países que aplica de forma mais benévola as regras que endurecem as políticas migratórias europeias.

Assim, identificaram-se vários tipos de respostas de diferente índole face ao intenso aumento das migrações registado no território português na última década: A-) a legalização ou regularização dos imigrantes, promovendo uma integração no mercado de trabalho formal, vinculando a residência a um contrato de trabalho e contrariando a subsistência da economia informal (mesmo quando as tentativas acabaram por não ter o sucesso desejado); B-) a adopção de um regime que favorece a aquisição da nacionalidade portuguesa, privilegiando a cidadania plena, mesmo que ainda persistam lacunas, inconsistências e desigualdades; C-) criação de uma estrutura institucional própria para as migrações, o Alto-Comissariado para a Imigração e o Diálogo Intercultural (ACIDI) com o objectivo de melhorar e promover a integração dos imigrantes. Dito organismo tem dado uma ampla gama de respostas às diferentes vertentes da integração dos imigrantes.

\footnotetext{
${ }^{37}$ PADILLA, Beatriz; AZEVEDO, Joana. "Territórios de diversidade e convivência cultural: considerações teóricas", p. 43-67; MENDES, Maria Manuela. "Bairro da Mouraria, território de diversidade: entre a tradição e o cosmopolitismo", p. 15-41.

${ }^{38}$ ACOSTA, Diego. "The Good, the bad and the ugly in EU Migration Law: is the European parliament becoming bad and ugly?".
} 
Por outro lado, ainda persistem um conjunto de situações que requerem acção. Torna-se necessário melhorar a intervenção com medidas concretas tendentes a reduzir a discriminação racial e étnica e a ultrapassar os efeitos perversos da actual crise que tem afectado mais os imigrantes que os nacionais. Importa ainda melhorar a percepção da sociedade portuguesa sobre a imigração em geral. ${ }^{39}$

Tendo agora em conta a emigração da população, e no actual momento de incerteza provocado pela crise, sabe-se que esta retomou um ritmo acelerado, especialmente no caso dos jovens qualificados nacionais que partem em direcção a alguns países da UE, a Angola e ao Brasil. Por outro lado, e contrariando a tendência crescente verificada até 2010, muitos imigrantes decidiram retornar aos seus países de origem em busca de novas oportunidades ou forçados pela improbabilidade e dificuldade de encontrar trabalho em Portugal. Neste sentido, o retorno dos brasileiros tem sido um dos acontecimentos mais retratados ao nível da comunicação social e académico. ${ }^{40}$

Para finalizar e tendo em conta o exposto, pode-se afirmar que a actual conjuntura representa sem dúvida um novo ponto de inflexão na história das migrações portuguesas, situação que dificulta qualquer conjectura sobre o que irá a acontecer nos próximos anos, salvo que o impasse pode demorar alguns anos.

\section{Bibliografia}

ACOSTA, Diego. "The Good, the bad and the ugly in EU Migration Law: is the European parliament becoming bad and ugly?" (The adoption of Directive 2008/15: The return directive), in European Journal of Migration and Law, v. 11, n. 1, 2009, p. 19-39.

BADIE Bertrand; BRAUMAN Rony; DECAUX, Emmanuel; DEVIN, Guillaume; WIHTOL DE WENDEN, Catherine. Pour un autre regard sur les migrations. Construire une gouvernance mondiale. Paris: La découverte, 2008.

BAGANHA, Maria. "As correntes emigratórias portuguesas no século XX e o seu impacto na economia nacional", in Análise Social, XXIX, n. 128, 1994, p. 959-980.

BAGANHA, Maria; FERRÃO, João; MALHEIROS Jorge M. (org.). Os Movimentos Migratórios Externos e sua incidência no Mercado de Trabalho em Portugal. Lisboa: Observatório do Emprego e Formação Profissional, 2002.

BAGANHA, Maria; MARQUES, José Carlos; GÓIS, Pedro. "New migrations, new challenges: immigration from Eastern Europe", in Revista Crítica de Ciências Sociais, n. 69,2004 , p. 95-115.

\footnotetext{
${ }^{39}$ PEIXOTO, IORIO, op. cit.; PADILLA, Beatriz; FRANÇA, Thais. "Direitos dos brasileiros e brasileiras na união europeia: o papel do Estado".

40 PEIXOTO, IORIO, op. cit.; PADILLA, FRANÇA, op.cit.
} 
. "Imigrantes em Portugal: uma síntese histórica", in Ler História, n. 56, 2009, p. 123-133.

BAGANHA, Maria; PEIXOTO, João. “Trends in the 90's: the Portuguese migratory experience", in BAGANHA, Maria (ed.). Immigration in Southern Europe. Oeiras: Celta Editora, 1997, p. 15-40.

BALDWIN-EDWARDS, Martin. "The emerging European immigration regime: some reflections on implications for Southern Europe", in Journal of Common Market Studies, v. 35, n. 4, 1997, p. 497-519.

CASTLES, Stephen; MILLER, Mark J. The Age of Migration. Palgrave Macmillan: Houndmills, 2009.

FERNANDES Ana; MIGUEL, José Pereira. Health and Migration in the Euroepan Union: Better Health for all in an inclusive society. Lisboa: Instituto Nacional de Saúde Doutor Ricardo Jorge, 2009.

FONSECA, Maria Lucinda. "Territorial Insertion - urban planning, Regional Development and local atraction policies", in VITORINO, A. (coord.). Immigration: opportunity or threat? Lisbon, Principia: FCG; Gulbenkian Immigration Forum, 2007, p. 97-140.

FONSECA, Maria Lucinda; MALHEIROS, Jorge Macaísta; SILVA, Sandra. "Portugal", in NIESSEN Jan et alii (eds.). Current Immigration Debates in Europe: A Publication of the European Migration Dialogue. Brussels/Lisbon: Migration Policy Group, 2007.

KING, Russell; ZONTINI Elisabetta. The role of gender in the South European mode. Papers n. 60, 2000, p. 35-52.

HARVEY, David. The Condition of Postmodernity. Oxford: Basil Blackwell, 1990.

MACHADO, Fernando Luís. "Quarenta Anos de Imigração Africana: Um balanço", in Ler História, n. 56, 2009, p. 135-165.

MALHEIROS, Jorge Macaísta. "New' immigration and regional development: current situation and opportunities for Portuguese regions", in Cadernos Sociedade e Trabalho, n. 2, 2002, p. 69-87.

- Portugal seeks balance of Emigration, Immigration. Country Profiles Information Source. Washington DC: Migratory Policy, 2002.

MARQUES, José Carlos. Os Portugueses na Suíça: Migrantes Europeus. Lisboa: Imprensa de Ciências Sociais, 2008.

MARQUES, José Carlos; GÓIS, Pedro. A emergência das migrações no feminino. Cascais: Princípia, 2011.

MENDES, Maria Manuela. "Bairro da Mouraria, território de diversidade: entre a tradição e o cosmopolitismo", in Sociologia, Revista da Faculdade de Letras da Universidade do Porto, Número temático: Imigração, Diversidade e Convivência Cultural, 2012, p. 15-41.

MIRANDA, Joana. Mulheres imigrantes em Portugal: memórias, dificuldades de Integração e projectos de vida. Estudos OI, n. 35. Lisboa: ACIDI, 2009.

OLIVEIRA, Catarina. Empresários de Origem Imigrante: Estratégias de Inserção 
Económica em Portugal. Coleção Teses, 2. Lisboa: ACIME, 2005.

PADILLA, Beatriz. "Acordos bilaterais e legalização: o impacto na integração dos imigrantes brasileiros em Portugal", in MALHEIROS, Jorge Macaísta (org.). Imigração brasileira em Portugal. Lisboa: ACIDI, 2007, p. 217-226.

. "Redes sociales de los brasileros recién Ilegados a Portugal: ¿solidaridad étnica o empatía étnica?", in Revista Alternativas. Cuadernos de Trabajo Social, n. 14, 2006, p. 49-61.

PADILLA, Beatriz; AZEVEDO, Joana. "Territórios de diversidade e convivência cultural: considerações teóricas", in Sociologia, Revista da Faculdade de Letras da Universidade do Porto, Número temático: Imigração, Diversidade e Convivência Cultural, 2012, p. 43-67.

PADILLA, Beatriz; FRANÇA Thais. "Direitos dos brasileiros e brasileiras na União Europeia: o papel do Estado", in OLAF, Jacob (ed.). Economia, parlamentos, desenvolvimento e migrações: as novas dinâmicas bilaterais entre Brasil e Europa. Rio de Janeiro: Konrad-Adenauer-Stiftung, 2012.

PADILLA, Beatriz; MATIAS, Raquel. "As migrações latino-americanas para Europa; uma análise retrospectiva para entender a mobilidade actual", in Migrações, n. 5, Lisboa: Observatório da Imigração, 2009, p. 19-35.

. "Migratory and nationality politics in Portugal: 're' or de'-ethnicisation?'".

Paper apresentado na 4⿳亠丷a Conferência Anual de IMISCOE, Cluster B3 sobre Migration and citizenship: legal status, mobilization and political participation, Sussex, Setembro 6-9, 2007.

PADILLA, Beatriz; ORTIZ Alejandra. "O acesso a nacionalidade como instrumento chave da cidadania. Barreiras e gaps que ainda persistem". Paper apresentado no VI Congresso da Associação Portuguesa de Ciência Política, Lisboa, Março 1-3, 2012.

PEIXOTO, João. "New Migrations in Portugal: Labour Markets, Smuggling and Gender Segmentation", in International Migration, v. 47, n. 3, 2009, p. 185-210.

- "País de imigração ou emigração? Mudança e continuidade no regime migratório em Portugal", in SOCIUS Working Papers Series, ISEG-UTL, 2004.

. "Strong markets, weak states: the case of recent foreign immigration in Portugal", in Journal of Ethnic and Migration Studies, v. 28 n. 3, 2002, p. 483-497. PEIXOTO, João; IORIO, Juliana. Crise, Imigração e Mercado de Trabalho em Portugal. Cascais: Principia, 2011.

PIRES, Rui Pena. "A Imigração", in BETHENCOURT, Francisco; KIRTI, Chaudhuri (orgs). História da Expansão Portuguesa. Volume V. Lisboa: Círculo de Leitores, 1999, p. 197-211

- Migrações e Integração: Teoria e aplicações à Sociedade Portuguesa. Oeiras: Celta Editora, 2003.

- "Mudanças na Imigração: uma análise das estatísticas sobre a população estrangeira em Portugal, 1998/2001", in Sociologia, Problemas e Práticas, n. 39, 2002, p. 151-166. 
PIRES, Rui Pena et alii. Portugal. Atlas das Migrações. Lisboa: Tinta da China, 2010.

RAMOS Madalena; FERREIRA Ana Cristina. "Marriage with Immigrants in Portugal, Global Perspectives on Marriage and International Migration". Seoul, Coreia: IUSSP, 2011.

REYNERI, Emilio. "Illegal immigration and the underground economy". Paper apresentado na Conferência The Challenges of immigration and integration in the European Union and Australia, Sydney, February, 18-20, 2003.

. "The role of the underground economy in irregular migration toltaly: cause or effect?", in Journal of Ethnic and Migration Studies, v. 24, n. 2, 1998, p. 313-331.

SALT, John. Current Trend on International Migration in Europe. Council of Europe: Strasbourg, 2006.

SASSEN, Saskia. Guests and aliens. New York: New Press, 1999.

WALL, Karin; NUNES, Cátia; MATIAS, Ana Raquel. Female Migration Vision. National Report - Portugal. Lisboa: Instituto de Ciências Sociais, 2006.

\section{Abstract}

\section{Migration flows in Portugal: from migration boom to slowdown in context of crisis. Balance and challenges}

Migration has been an increasingly present phenomenon in the Portuguese society, both with regard to immigration and to emigration. This article presents a brief overview of this recent history, describing not only the flows and their main features but also the European and national context, with a special connection to legislative changes, in which the migration flows are developed. The article highlights how Portugal has suffered an unprecedented migration boom, which is influenced by the current crisis, leading not only to a decline in immigration, but also to a revival of the emigration phenomenon.

Keywords: Portugal; Migration boom; Immigration policies; Integration policies; Southern European model.

Recebido para publicação em 04/09/2012.

Aceito para publicação em 28/10/2012.

Received for publication in September, 04 $4^{\text {th }}, 2012$.

Accepted for publication in October, 28 ${ }^{\text {th }}, 2012$. 